\title{
Currículo do Curso de Medicina da Faculdade de Medicina da Universidade de São Paulo - FMUSP
}

\author{
Milton Arruda Martins*
}

\begin{abstract}
Martins MA. Currículo do curso de medicina da Faculdade de Medicina da Universidade de São Paulo. Rev Med (São Paulo) 2003 jan.-dez.;82(1-4):81-3.

RESUMO: A primeira turma a ter tido contato com o currículo nuclear está se formando, e esse fato suscita vários questionamentos. Para respondê-los, ainda que em parte, uma avaliação está em curso. O currículo nuclear possibilitou aos estudantes oportunidade de ampliar e individualizar sua formação acadêmica, sem, no entanto, deixar de atender alguns requisitos, como a ênfase na formação geral. Outros pontos considerados foram a centralização no aluno, a atividade didática, a relação professoraluno e a integração das áreas básica e clínica. Alguns foram sucedidos, outros não.
\end{abstract}

DESCRITORES: Currículo. Educação médica. Escolas médicas.

A primeira turma do currículo atual iniciou o curso em 1998, estando concluindo o sexto ano. A Comissão de Graduação da FMUSP está iniciando uma avaliação desse currículo, visando o aperfeiçoamento da formação médica e adequar o currículo às Diretrizes Curriculares, recentemente aprovadas pelo Ministério da Educação e Cultura.

Um dos objetivos centrais do novo currículo foi oferecer uma formação geral a todos os alunos de medicina (o segmento nuclear do currículo, que é o conjunto dos conhecimentos, habilidades e atitudes necessários à formação geral do médico) e, ao mesmo tempo, oferecer a oportunidade de haver mais autonomia e iniciativa por parte dos alunos no sentido de complementar a sua formação (o segmento complementar do currículo).

O segmento nuclear do currículo corresponde a 70 a $80 \%$ da carga horária do primeiro ao oitavo semestres do curso e é igual para todos os alunos. O segmento complementar corresponde a até $30 \%$ da carga horária, do primeiro ao oitavo semestres, e constitui-se de atividades diversificadas, de iniciação científica, estágios de formação profissional, disciplinas optativas, atividades de formação para o ensino/aprendizado (monitorias) e atividades de extensão de serviços à comunidade. Além disso, o aluno é incentivado a cursar disciplinas em outras unidades da USP, com o objetivo de vivenciar, de uma forma mais ampla, a vida em uma universidade. Nos dois últimos anos (internato), não há atividades optativas.

Por outro lado, a definição dos conteúdos curriculares deveria levar em conta um critério fundamental que é o correspondente às necessidades de saúde das pessoas e das comunidades de nosso país.

A filosofia educacional que norteou a implantação do novo currículo pode ser, assim, caracterizada:

1. Resposta à crescente e incontrolável sobrecarga de informações que envolve o ensino médico. Não é possível ensinar todos os conteúdos. Por outro lado, muitos dos conhecimentos básicos e clínicos em pouco tempo estão ultrapassados. Nesse sentido, o

Professor titular do Departamento de Clínica Médica da Faculdade de Medicina da Universidade de São Paulo.

Endereço para correspondência: Milton de Arruda Martins. Departamento de Clínica Médica, FMUSP. Av. Dr. Arnaldo, 455 - Sala 1216. 01246-903 - São Paulo, SP. E-mail: mmartins@usp.br 
currículo deve se concentrar nos conhecimentos que são fundamentais de cada área e fornecer ao aluno uma formação mais geral e que permita que ele se atualize nessas áreas;

2. Resgate da atividade didática dos docentes não envolvidos (ou muito pouco envolvidos) na atual graduação médica. A valorização da atividade de ensino de graduação, com reconhecimento dessa atividade nos concursos e nos sistemas de promoção acadêmica faz parte importante desse projeto;

3. Aprimoramento dos métodos pedagógicos utilizados na graduação médica. O objetivo a ser atingido é deslocar o ensino/aprendizado em uma lógica baseada na transmissão de conhecimento para uma lógica centrada no aprendizado do que é mais importante para a formação geral do médico. O método pedagógico central é a exposição do aluno, desde o primeiro dia de aula a problemas reais de saúde de pessoas e comunidades, de complexidade compatível com o momento do curso e em diversos cenários de atendimento (unidades básicas de saúde, ambulatórios em hospitais, hospital secundário e hospital terciário, unidades de internação, unidades de emergência e de terapia intensiva). Nesse sentido, há uma diminuição progressiva de atividades teóricas, com grupos maiores de alunos e sua substituição por atividades práticas, em pequenos grupos e atendimento supervisionado;

4. Identificação do aluno, isto é, tirá-lo do anonimato, recuperando a relação professor/aluno. Uma relação mais próxima entre professores e alunos deveria ser atingida com o ensino em pequenos grupos, as atividades de iniciação científica e de atendimento supervisionado e os grupos de tutoria;

5. Incentivo ao auto-aprendizado através de atividades complementares eletivas: iniciação científica, iniciação profissional, iniciação ao ensino médico, disciplinas optativas, ligas acadêmicas e extensão de serviços à comunidade, visando preparar o aluno para a educação continuada;

6. Preocupação central com a qualidade de vida do aluno de medicina, reconhecendo todas as dificuldades e problemas que fazem parte da formação médica;

7. Incentivo à participação permanente dos docentes envolvidos no curso e dos alunos em todas as decisões do curso.

A revisão da estrutura curricular atendeu, também, a alguns outros objetivos:

1. Destinar carga horária substancial ao ensino de biologia molecular e celular, dentro da carga horária destinada ao aprendizado básico;

2. Promover uma integração maior entre as disciplinas do ciclo básico. Aprendizado básico não é, aqui, compreendido como tradicionamente, como sendo o aprendizado apenas dos aspectos biológicos da medicina: anatomia, histologia, fisiologia, por exemplo, mas como todos os conhecimentos e habilidades necessários para iniciar o aprendizado clínico do estudante de medicina;

3. Promover uma integração maior entre as disciplinas do ciclo clínico. O ensino clínico é ministrado com ênfase na semiologia (relação médico-paciente, anamnese, exame clínico e raciocínio clínico) e nas áreas gerais de formação do médico (clínica médica, cirurgia, pediatria e ginecologia-obstetrícia). O ensino de áreas mais específicas como dermatologia, oftalmologia e otorrinolaringologia é centrado naquilo que todo médico deve saber daquela área;

4. Colocar o aluno, desde o primeiro semestre, em contato com conteúdos clínicos e estender o ensino de conteúdos básicos até o último ano do curso. No primeiro semestre do curso, por exemplo, foi incluída a disciplina "Introdução à Medicina" em que há conteúdos de saúde da comunidade, suporte básico de vida, relação médico-paciente, introdução ao hospital, cuidados de enfermagem, entre outros;

5. Destinar uma carga horária substancial à formação humanística do estudante de medicina, e à formação para a cidadania e responsabilidade social;

6. Eliminar repetições desnecessárias durante o ensino básico e clínico;

7. Rever o conteúdo de diversas disciplinas, para que fosse mais centrado naquilo que realmente todo médico deve saber;

8. Ao constatar a existência de períodos ociosos, a redução dos períodos destinados a várias disciplinas não implicou, muitas vezes, em redução do conteúdo ministrado;

9. Oferecer a possibilidade de que atividades de iniciação científica e estágios supervisionados possam fazer parte do currículo médico;

10. Aproximar professores e alunos, estabelecendo um sistema com tutores (orientadores) para cada grupo de alunos;

11. Ampliação do ensino em ambulatório, de preferência com atividades fora do ambiente hospitalar, em unidades básicas de saúde e programas de saúde da família;

12. Oferecer aos alunos treinamento sólido também em promoção da saúde, prevenção, rastreamento e reabilitação.

Alguns desses objetivos foram atingidos, outros não. Por exemplo, a integração entre o chamado ensino básico e o clínico ainda é muito menor do que deveria ser. 
Muitas disciplinas não definiram claramente seus objetivos educacionais, no sentido de estabelecer os conhecimentos, habilidades e atitudes de sua área de conhecimento que todos os médicos devem adquirir. Há necessidade de valorizar muito mais a atividade docente ligada ao ensino de graduação.

Outros objetivos serão atingidos brevemente. A ampliação do ensino em ambulatório e do treinamento em promoção da saúde serão alcançados com o programa de treinamento em Atenção Básica à Saúde que será implantado a partir de 2004. Haverá atividades em unidades básicas de saúde para os alunos do primeiro, do terceiro e do quinto anos.

A revisão de nosso currículo será feita através de uma avaliação de todas as disciplinas existentes e com participação de docentes e alunos. Por outro lado, estamos avaliando os alunos formados no novo currículo, no sentido de ver se os objetivos da mudança curricular foram atingidos e como são seus conhecimentos e habilidades médicas em comparação a alunos formados pelo currículo anterior.

Martins MA. Currículo do curso de medicina da Faculdade de Medicina da Universidade de São Paulo. Rev Med (São Paulo) 2003 jan.-dez.;82(1-4):81-3.

The first class to have contact with the nuclear curriculum is now graduating, and various questions may arise from this fact. In order to answer them, an evaluation is under development. The nuclear curriculum has allowed students to broad and to individualise their academic training, and at the same time fulfilling requisites such as the emphasis on a general formation. Other points that have been considered were the centralisation on the student, didactic activity, teacher-student relationship, and integration between the basic and clinic fields. Some of these were accomplished - others, were not.

KEYWORDS: Education, medical. School, medical. Curriculum. 